\title{
TECNOLOGIAS ASSISTIVAS NA EDUCAÇÃO DE ESTUDANTES SURDOS
}

\author{
Amanda Síntia Santos da Silva ${ }^{1}$ \\ Fabiana Maria da Silva ${ }^{2}$
}

\section{RESUMO}

O referente trabalho vem mostrar a importância das tecnologias assistivas no processo educacional de estudantes surdos, partindo da história e trajetória da educação dos surdos até o avanço das tecnologias assistivas. Sendo assim, a pesquisa tem como objetivo analisar a utilização dessas tecnologias como recurso nas práticas pedagógicas no ensino-aprendizagem dos alunos surdos. O estudo, de cunho qualitativo e exploratório, foi realizado a partir de pesquisa bibliográfica. Os resultados evidenciam os recursos tecnológicos na educação dos alunos surdos e a utilização das práticas pedagógicas dos docentes em sala de aula.

Palavras-chave: Tecnologia assistiva. Surdos. Aprendizagem. Inclusão.

Data de submissão: 27/05/2020

Data de aprovação: $28 / 06 / 2020$

\section{INTRODUÇÃO}

As tecnologias estão influenciando cada vez mais o nosso modo de vida, a forma como nos comunicamos e, sobretudo, como aprendemos. Acompanhando essa evolução, as tecnologias assistivas também ganham grande expressão. Tecnologias assistivas (TA) são todo arsenal que pode ser utilizado por docentes em suas práticas pedagógicas como recurso para o ensino-aprendizagem de estudantes com necessidades especiais. Dentro desse grande universo, destacamos nessa pesquisa os estudantes surdos

O debate sobre TAs no processo escolar de estudantes surdos vêm sendo motivo de muitas pesquisas no meio acadêmico, principalmente a partir dos avanços tecnológicos na área da educação inclusiva. Vários recursos e ferramentas surgiram para serem explorados em sala de aula como ferramentas de auxilio pedagógico. Toda essa tecnologia vem sendo 
utilizada pelos docentes e discentes no sentido de desenvolver um trabalho de qualidade no ensino e na aprendizagem dos alunos surdos.

Antes de avançar no assunto, é importante esclarecer a diferença entre surdo e deficiente auditivo. Segundo a Secretaria de Educação Especial do Ministério da Educação (1997), denomina-se "deficiência auditiva" a diminuição da capacidade de percepção normal dos sons. Com base nesta teoria usaremos no presente trabalho o termo "surdo".

Esta pesquisa busca analisar, a partir de um estudo bibliográfico, a importância das tecnologias como recurso no ensino-aprendizagem dos alunos surdos. Segundo a Lei Brasileira de Inclusão (LBI), a acessibilidade é direito que garante a pessoa com deficiência ou com mobilidade reduzida viver de forma independente e exercer seus direitos de cidadania e de participação social (LBI, 2015). A partir dessa lei podemos afirmar que não devemos privar esses estudantes de direito adquirido, que é desenvolver seus processos de aprendizagem.

A pesquisa partiu do interesse sobre como as tecnologias assistivas podem ser de grande proveito no ensino-aprendizagem dos alunos surdos nas aulas. A Educação Inclusiva nasceu do interesse de como relacionar a educação dos surdos com as tecnologias assistivas, a fim de auxiliar o professor em suas práticas pedagógicas e o aluno em sua formação.

\section{REFERÊNCIAL TEÓRICO}

Para embasar o tema proposto neste estudo algumas pesquisas foram realizadas. Entre os principais autores destacamos Strobel (2009), Kenski (2015), e Bersch (2019) que nos ajudaram a aprofundar os conhecimentos e definições sobre as tecnologias assistivas para alunos surdos.

\section{Um breve relato da história da educação dos surdos}

A educação dos surdos vem de um longo caminho, desde muito tempo atrás. Havia uma discriminação na sociedade, construída a partir do pensamento de alguns teóricos que afirmavam que os estudantes surdos seriam incapazes de desenvolver a aprendizagem, pelo fato de não obterem a oralidade formal.

Esses alunos tiveram suas vidas mudadas a partir dos estudos científicos de médicos e religiosos da época, pois entendiam que o fato deles não falarem não os tornavam pessoas capazes de evoluir em seu aprendizado e sua autonomia. 
A esse respeito Strobel (2009) afirma que a surdez não impediria e nem afetaria os alunos surdos na sua aprendizagem nem na sua capacidade de desenvolver suas habilidades tanto na leitura quanto na escrita.

A partir de um ato de coragem e determinação de Charles Michel de 1'Epée, o pai da educação pública para surdos no mundo, surge a ideia de criação da primeira escola para surdos, na França, em 1755. L’Epée saía pelas ruas de Paris a procura de surdos para ensinálos a língua de sinais. Reconhecido pela Assembleia Nacional Francesa como um benfeitor da humanidade, l'Epée usou seu patrimônio para integrar pessoas com deficiência auditiva à sociedade.

Com relação à educação para surdos no Brasil, encontramos ainda em Strobel (2009) a referência de que esse tipo de educação passou a ser interesse de D. Pedro II com a chegada do professor Eduard Huet, o pai da Língua Brasileira de Sinais (LIBRAS).

Esse professor apresenta a proposta de criação de uma escola para surdos no Brasil. Anos depois de criada a escola, a mesma torna-se o Instituto Nacional de Educação dos Surdos (INES). Conforme cita Strobel

\begin{abstract}
as primeiras instituições para alunos especiais foram o Instituto dos Meninos Cegos e o Instituto Nacional de Educação dos Surdos construída no século XIX. É uma instituição que foi criada com uma modalidade de ensino oferecida para os alunos surdos e cegos com professores capacitados e qualificados na área da educação especial. (STROBEL, 2009, p. 24).
\end{abstract}

É importante dizer que essa educação que os surdos recebiam era voltada para o processo de comunicação, e não para a construção do conhecimento. Conforme afirma Soares (1999):

\footnotetext{
a educação do surdo foi a educação reservada àqueles que não frequentariam a escola, mas necessitariam de um tipo de ensino que visasse supri-lo naquilo que the faltava, no caso do surdo, a mudez. Daí todas as metodologias empregadas, quer tenham sido através de gestos, quer tenham sido através da escrita, ou da fala, preocuparam-se fundamentalmente com a mudez, ou seja, com a possibilidade de estabelecer formas de comunicação simples. (SOARES, 1999, p. 115).
}

Percebemos com isso que a educação voltada para estudantes surdos esteve historicamente ligada a processos pouco inclusivos. Atualmente, temos dispositivos legais que garantem a inclusão, formação de professores e demais direitos.

\title{
A legislação na educação dos surdos
}

A educação voltada para alunos surdos e alunos com deficiência auditiva está acobertada pela legislação específica. Essa lei trata da educação inclusiva, considerada como uma 
modalidade de ensino. Atualmente, a legislação brasileira assegura a educação inclusiva através de vários dispositivos normativos, como a Constituição Federal (CF,1988), a Lei Brasileira de Inclusão (LBI), entre outras.

Com a homologação da lei no 10. 436, instituída pelo Ministério da Educação (MEC) em 2002, fica assegurado que esses alunos tenham assistência quanto à sua formação escolar. A Língua Brasileira de Sinais (LIBRAS) passa a ser incluída nos currículos escolares, além de outros recursos que facilitem a comunicação e que tenham a finalidade de interagir tanto com os surdos quanto os ouvintes.

A lei $\mathrm{n}^{\mathrm{o}} 10.436$ define a Língua Brasileira de Sinais (LIBRAS) como a forma de comunicação e expressão em que o sistema linguístico de natureza visual-motora, com estrutura gramatical própria, constitui um sistema linguístico de transmissão de ideias e fatos, oriundos de comunidades de pessoas surdas do Brasil. Essa exigência da lei demanda, consequentemente, a necessidade de formação docente em LIBRAS (Língua Brasileira de Sinais).

O decreto $\mathrm{n}^{\mathrm{o}}$ 5.626/2005 tem como finalidade complementar duas leis: a 10.436/2002 que regulamenta a LIBRAS como uma língua oficial da comunidade surda, e também o Art. 18 da lei $n^{\circ} 10.098$ que trata especificamente da acessibilidade na comunicação.

É importante ressaltar que tanto a lei n. 10.436 quanto o decreto $\mathrm{n}^{\mathrm{o}} 5.626$ asseguram a educação dos alunos surdos e fica evidente a importância de investir na formação e qualificação dos profissionais da educação. No art. 14, § VII, do decreto n. 5.626, está assegurada a qualificação docente quanto ao acesso às novas tecnologias de informação e comunicação, bem como recursos didáticos para apoiar a educação de alunos surdos.

Embasado neste decreto, encontramos apoio legislativo para defender a utilização de recursos tecnológicos no processo educacional desses estudantes, pois tanto a lei $\mathrm{n}^{\mathrm{o}} 10.436$ quanto o decreto $\mathrm{n}^{\circ} 5.626$ são grandes aliadas ao apoio pedagógico específico, pois inclue m, além da formação docente, currículos e projetos pedagógicos que contemplam as necessidades desses alunos, conforme cita o decreto $n^{0} 5.626 / 2005$ :

Art.14. As instituições federais de ensino devem garantir, obrigatoriamente, às pessoas surdas acesso à comunicação, à informação e à educação nos processos seletivos, nas atividades e nos conteúdos curriculares desenvolvidos em todos os níveis, etapas e modalidades de educação, desde a educação infantil até à superior. (DECRETO 5.626/2005).

Segundo a Constituição Federal, "A educação é um direito de todos e dever do Estado e da família. Será promovida e incentivada com a colaboração da sociedade, visando ao pleno desenvolvimento da pessoa, seu preparo para o exercício da cidadania e sua qualificação para 
o trabalho". (CF, 1988). A constituição evidencia que a educação é um direito que abrange a todos, inclusive os surdos.

A educação se constitui como uma possibilidade de alcançar dignidade e dentre outras coisas, o acesso ao mercado de trabalho. Para que a educação dos surdos seja realmente eficiente é necessário discutir a importância da formação dos professores nesse contexto, uma vez que são os docentes que estão na sala de aula, recebendo esses estudantes.

Para Kenski (2015), é necessário que haja uma formação tecnológica continuada de docentes para que tais ferramentas sejam usadas como recurso pedagógico na escola regular. Essa afirmação corrobora com a Lei Brasileira de Inclusão (LBI) que afirma em seu art. 74 que é garantido à pessoa com deficiência acesso a produtos, recursos, estratégias, práticas, processos, métodos e serviços de tecnologias assistivas que maximizem sua autonomia, mobilidade pessoal e qualidade de vida (LBI, 2015, p. 35).

Sobretudo, é direito do aluno surdo o acesso às estratégias pedagógicas específicas, recursos e serviços da tecnologia de apoio para a construção de sua autonomia, conforme os dispositivos normativos.

\section{As tecnologias como recurso de aprendizagem}

O processo de ensinar e aprender já não é mais o mesmo modelo praticado no século $\mathrm{XX}$, em que as disciplinas eram desarticuladas, os estudantes eram passivos e os professores eram os donos do saber. Atualmente, o processo de ensino-aprendizagem é mediado pelo professor e os estudantes são colocados como centro do processo e sujeitos de suas próprias construções.

Dentro desse contexto, as tecnologias são utilizadas como instrumentos que potencializam as aprendizagens, dinamizam as interações, as relações com o conhecimento e suas possibilidades. Esse novo cenário tem apresentado grandes alternativas para a educação dos surdos, pois é possível, mediante as Tecnologias Assistivas (TA), construir novas possiblidades de acesso a conteúdos e metodologias que ajudam no desenvolvimento das aprendizagens.

Para Bersch (2017), as tecnologias assistivas têm o objetivo de garantir a facilidade da aprendizagem, de maneira mais significativa, e também promover o desenvolvimento educacional com qualidade e autonomia, a fim de socializar os deficientes auditivos no âmbito escolar. Para a autora, há

(...) auxílios que incluem vários equipamentos (infravermelho, FM), aparelhos para surdez, sistemas com alerta táctil-visual, celular com mensagens escritas e chamadas 
por vibração, software que favorece a comunicação ao telefone celular transformando em voz o texto digitado no celular e em texto a mensagem falada. Livros, textos e dicionários digitais em língua de sinais. Sistema de legendas (closecaption/ subtitles) e avatares. (BERSCH, 2017, p. 10).

Outra definição que corrobora com nosso estudo é a de Quadros (2010). Ela diz que (...)Tecnologias assistivas são recursos e serviços que visam a facilitar o desenvolvimento de atividades da vida diária por pessoas com deficiência. Procuram aumentar capacidades funcionais e, assim, promover a autonomia e a independência de quem as utiliza. (QUADROS, 2010, p. 62).

As duas definições concordam que as TAs facilitam os processos educacionais e demais processos da vida de quem as utilizam. Bersh (2017) traz uma definição um pouco mais abrangente, dizendo que as

(...) tecnologias assistivas incluem um conjunto de conhecimentos interdisciplinares, artefatos, métodos e serviços que auxiliam as atividades de vida diária e a participação de $\mathrm{PcD}$, incapacidades ou mobilidade reduzida, com desígnio de prover autonomia, independência, qualidade de vida e inclusão social. Essas tecnologias podem reduzir barreira enfrentada por profissionais da saúde no atendimento dessa população e a utilização desse recurso, muitas vezes, torna-se essencial para efetivação de estratégias educativas. (BERSCH, 2017, p. 11).

A partir das tecnologias assistivas podemos ter diversos recursos que podem facilitar o ensino e transformar o mundo dos surdos com novos significados. Sabemos da complexidade que está subjacente ao processo educacional, que se potencializa quando discutimos esse processo no universo da cultura dos surdos, uma vez que possuem linguagem e modos próprios de apropriação do mundo.

A partir dos dispositivos normativos que regulam a educação inclusiva, as escolas passaram a receber muitos estudantes surdos. Para Rodrigues (2015), essa presença traz novos desafios ao espaço escolar, já que precisa lidar com a diversidade desses alunos e também com a diferença linguística e cultural dos alunos surdos. (RODRIGUES, 2015, p.113).

Faz-se necessário ampliar a autonomia dos alunos surdos, transformando as práticas educacionais e criando ambientes inclusivos através da tecnologia assistiva. Atualmente temos um cenário favorável, por assim dizer, com relação ao número de possibilidades tecnológicas como softwares e aplicativos que podem ser utilizados como recursos de aprendizagem. 
Temos como exemplo alguns aplicativos como: Whatsapp, Facebook, Instagram, entre outros, que ao serem utilizados como ferramentas na educação podem ser recursos tanto para a socialização quanto para as atividades e trabalhos em grupos dentro ou fora do âmbito escolar. Segundo Bersch (2017), a tecnologia assistiva pode ser vista, no contexto da tecnologia educacional, como a tecnologia que justifica o fato de que ela serve à pessoa com deficiência que necessita desempenhar funções do cotidiano de forma independente.

Com relação aos softwares e aplicativos há alguns que se destacam em textos acadêmicos. O Vlibras possui várias ferramentas. Uma delas serve para interpretação de conteúdo, sites, áudios e textos para a Língua Brasileira de Sinais - LIBRAS, podendo ser instalado em celulares e computadores.

Outra ferramenta é a WIKILIBRAS, um sistema de correção e inclusão de novos sinais. Temos também como ferramenta o Hand Talk. Esse aplicativo transforma as imagens e textos em linguagem de sinais. Outra ferramenta muito interessante é o Alfabeto Libras, criado pelo projeto Beethoven e que, de forma dinâmica, torna a comunicação mais fácil.

Entre esses recursos tecnológicos temos uma grande vantagem de serem gratuitos e podendo ser operado off-line, facilitando assim o uso dentro ou fora do ambiente escolar, atingindo não só a socialização e aproximação dos ouvintes dos alunos surdos, mas facilitando o aprendizado entre si.

Isso nos leva a refletir sobre a relevância no aprendizado dos alunos surdos, pois, através das tecnologias assistivas, terão facilidade na compreensão das disciplinas que transcorrem no âmbito escolar.

\section{METODOLOGIA}

A presente pesquisa possui natureza qualitativa, que nos parece mais indicada para as pesquisas em educação, sendo mais contextualizada e profunda quanto à busca das respostas. Para validar os resultados quanto aos objetivos na coleta de dados, optamos por realizar uma pesquisa exploratória, a partir de levantamento bibliográfico.

Segundo Boccato (2006, p. 266) a pesquisa bibliográfica "busca a resolução de um problema (hipótese) por meio de referenciais teóricos publicados, analisando e discutindo as várias contribuições científicas".

As pesquisas foram realizadas nas plataformas Scielo, Google Acadêmico e Revista Cientifica a partir dos termos: tecnologia assistiva, surdos, aprendizagem e inclusão. 
Após essa primeira seleção, os trabalhos foram lidos, seguindo as etapas sugeridas por Gil (2008). Foram estabelecidas relações entre essas informações e o problema proposto, além de analisar a consistência das informações e dos dados apresentados pelos autores. A partir dos dados obtidos, realizou-se a análise e interpretação das informações para maior compreensão e aprofundamento sobre o tema abordado.

\section{ANÁLISE E RESULTADOS}

A pesquisa revelou que a educação dos surdos vem evoluindo historicamente. Nos últimos anos esse processo teve um grande avanço, principalmente na perspectiva da comunicação entre ouvintes e surdos, por conta das tecnologias assistivas que trouxeram mais facilidade na interação com os estudantes surdos, dentro e fora da sala de aula. A Língua Brasileira de Sinais (LIBRAS) aos poucos vem tomando espaço nas escolas e está apoiada na lei 10.436/2002, ganhando mais abrangência a partir das tecnologias assistivas e os aplicativos de comunicação.

A evolução histórica da educação dos surdos está ligada diretamente ao contexto da relação entre tecnologia e educação. Com relação a isso, esta pesquisa constatou que a tecnologia vem ocupando cada vez mais espaços na vida de todos, em especial facilitando a vida educacional dos alunos surdos. As tecnologias estão cada vez mais trazendo autonomia e facilitando a aprendizagem, além de incluir esses alunos no meio em que antes não estavam inseridos.

Para confirmar esse processo, buscamos identificar, a partir da literatura, os principais aspectos que justificam a utilização das tecnologias assistivas na educação dos surdos.

\section{Tecnologias assistivas e a inclusão do estudante surdo}

Hoje, muitos defendem a utilização das TAs para aprendizagem dos estudantes surdos, destacando a importância de disponibilizá-las também para os estudantes ouvintes, para que o ambiente da sala de aula seja realmente inclusivo e interativo.

Estas ferramentas devem ser utilizadas no auxílio dos estudantes da educação especial em seu processo de aprendizagem e independência, porém, a temática das TAs, especificamente para surdos, deveria ser mais difundida no meio acadêmico.

A leitura dos artigos indica que as tecnologias podem ser utilizadas como ferramenta pedagógica pelos docentes, como vimos em Kenski (2012). A autora reforça essa afirmação quando fala sobre as possibilidades da utilização das tecnologias na educação, pois elas dão 
origem a comunidades para o desenvolvimento partilhado de programas, objetos de aprendizagem, bibliotecas virtuais e arquivos temáticos em todas as áreas do conhecimento, para o uso nas mais diferentes situações, incluindo o ensino. (KENSKI, 2012, p. 124).

Ao fazermos uma síntese das informações encontradas, foi possível observar que a argumentação extraída dos artigos pesquisados se agrupa a partir de duas perspectivas: a da aprendizagem e da inclusão. Dos 6 (seis) artigos pesquisados, 5 (cinco) concluem que as tecnologias assistivas utilizadas como recursos pedagógicos podem contribuir com o ensinoaprendizagem dos surdo.

Os referidos artigos discutem que a utilização eficiente de aplicativos em dispositivos móveis é um percurso estratégico para melhor alcançar a educação dos surdos, assumindo o fato de que as tecnologias assistivas provocaram mudanças radicais na educação destes alunos.

Encontramos em Kenski (2012), uma das autoras do nosso referencial teórico, reforço para essa argumentação, quando coloca que "as propostas das tecnologias da informação e comunicação (TICs) mostram a relevância do uso das tecnologias como recursos nas escolas públicas" (KENSKI, 2012, p. 44).

Muitos autores defendem a utilização das tecnologias assistivas para os estudantes surdos na perspectiva de aprendizagem e também na perspectiva inclusiva, pois ressalta a importância de que essas tecnologias estejam disponíveis também para os estudantes ouvintes e professores como forma de inclusão na sala de aula, uma vez que os alunos surdos precisam interagir com pessoas e compartilhar conhecimentos.

Bersch (2017) também destaca esse aspecto quando argumenta a importância da utilização das ferramentas tecnológicas na educação, pois funcionam de forma facilitadora na educação dos alunos surdos, tanto nas escolas particulares quanto das redes públicas de ensino.

Em contrapartida, a pesquisa também revelou que a disponibilização de recursos tecnológicos e formação para docentes ainda se constituem como obstáculos no sentido de colocar em prática metodologias que explorem de maneira eficiente as tecnologias ass istivas nas escolas.

Embasado nos pressupostos dos teóricos que fundamentaram este estudo, entendemos que as tecnologias assistivas podem criar mais ambientes inclusivos como recursos tecnológicos, transformando as práticas educacionais e proporcionando mais aprendizagem e autonomia para os alunos surdos. 


\section{CONSIDERAÇÕES FINAIS}

Esta pesquisa teve como objetivo geral identificar a utilização de tecnologias assistivas para o ensino e aprendizagem dos surdos. A referida análise revelou que a tecnologia assistiva não é algo tão novo no meio educacional, porém não muito utilizado, embora seja de grande relevância no uso nas práticas pedagógicas para auxiliar na aprendizagem dos alunos surdos.

Com esse estudo chegamos à conclusão que é possível a utilização do uso das tecnologias assistivas nas práticas pedagógicas como recursos na aprendizagem e inclusão dos alunos surdos. Para isso ainda existe um grande desafio a ser percorrido. Grandes barreiras a serem derrubadas são a formação de docentes e os recursos tecnológicos dentro das escolas. Isso fará com que o "leque" da comunicação e da informação seja aberto, facilitando tanto o ensino quanto a aprendizagem desses alunos.

Sabemos que a complexidade dessa temática e de todas as questões que lhes são subjacentes não permite que o debate seja esgotado nessa breve pesquisa, porém a partir dos estudos aqui analisados, fica claro que as tecnologias assistivas na educação de estudantes surdos é uma ferramenta com muitas possibilidades, devendo ser utilizadas na prática pelos docentes e discentes no ensino regular, pois ajudam no desenvolvimento de aprendizagens e inclusão e, consequentemente, na construção da cidadania desses estudantes.

\section{REFERÊNCIAS}

BERSCH, R. 2013. Introdução à Tecnologia Assistiva. Disponível em: http://www.assistiva.com.br/Introducao_Tecnologia_Assistiva.pdf. Acesso em: 27 out. 2019.

BERSCH, R. 2009. Introdução à tecnologia assistiva. CEDI - Centro Especializado em Desenvolvimento Infantil. Porto Alegre: 2008.

BRASIL. Decreto 5.626 de 22 de dezembro de 2005. Regulamenta a Lei n o 10.436, de 24 de abril de 2002 que dispõe sobre a Língua Brasileira de Sinais - Libras.

BRASIL. LDB. Lei 9394/96. Acesso em: https://presrepublica.jusbrasil.com.br/legislacao/109224/lei-de-diretrizes-e-bases-lei-9394-96. Acesso em: 27 out. 2019.

BRASIL. LBI. Lei Brasileira de Inclusão. Disponível em: http://www.planalto.gov.br/ccivil_03/_ato2015-2018/2015/lei/113146.htm. Acesso em: 02 nov. 2019. 
BRASIL. Parâmetros Curriculares Nacionais. PCN. Portal MEC. Disponível em: http://portal.mec.gov.br/seb/arquivos/pdf/livro01.pdf. Acesso em: 10 nov. 2019.

CASSIANO, P. V. O surdo e seus direitos: os dispositivos da lei 10.436 e do decreto 5.626. Revista Virtual de Cultura Surda. Disponível em: http:/editora-araraazul.com.br/site/admin/ckfinder/userfiles/files/3\%C2\%BA\%20Artigo\%20de\%20Cassiano.pdf Acesso em: 15 dez. 2019.

EDUCAR EM REVISTA. Curitiba, Brasil, Edição Especial n. 2/2014, p. 17-31. Editora UFPR. Curitiba. Disponível em: http://basenacionalcomum.mec.gov.br/. Acesso em: 02 nov. 2019.

KENSKI, V. M. Educação e tecnologias: o novo ritmo da informação. Campinas: Editora Papirus, 2012. 141p.

PERLIN, G.; STROBEL, K. História cultural dos surdos: desafio contemporâneo. Disponível em: http://www.scielo.br/pdf/er/nspe-2/03.pdf. Acesso em: 08 nov. 2019.

QUADROS, Ronice Muller de. Educação de surdos: a aquisição da linguagem. Porto Alegre: Artmed, 2008.

RIOS, B. D.; DIAS, L.; ROSSI, C. M. S. O ensino de ciências e biologia para alunos surdos. Perspectivas, desafios e possibilidades. Revista Partes. 2019. Disponível em: https:/www.partes.com.br/2019/12/19/o-ensino-de-ciencias-e-biologia-para-alunos-surdosperspectivas-desafios-e-possibilidades/. Acesso em: 19 dez. 2019.

STROBEL, Karin. História dos surdos. Educar em Revista. Curitiba, Brasil. Edição Especial. n. 2/2014, p. 17-31. Editora UFPR, 2008. 